\title{
A NEW FAMILY OF POWER SUPPLIES FOR THE LNLS ORBIT CORRECTORS
}

\author{
C. Rodrigues, A. R. Silva, L. H. Oliveira, LNLS, Campinas, Brazil.
}

\begin{abstract}
Recently the substitution of the older family of orbit corrector power supplies of the LNLS electron storage ring was proposed and a new family has been developed. The new model incorporates additional features such as natural ventilation, unit power factor and shorter response time to reference changes. Moreover, higher efficiency and lower weight and size were obtained. At the moment eight units are operating with storage ring orbit correctors, with current and output voltage up to $10 \mathrm{~A} / 10 \mathrm{~V}$.

This family has three stages of power processing. The first one is a power factor corrector using the boost topology, which gives to the second stage a DC voltage about $400 \mathrm{~V}$ with regulation and ripple better than $1 \%$. The second stage is an isolated half-bridge with two symmetric adjustable DC outputs from 0 to $40 \mathrm{~V}$. The last stage consists of a bipolar series linear regulator using Bipolar Transistors (BJT). Some results obtained for this power supply were: output current ripple and one day stability better than $150 \mathrm{ppm}$, reference voltage step response better than $500 \mathrm{~A} / \mathrm{s}$ with the existing orbit corrector magnet, efficiency higher than $62 \%$ and power factor better than $98.5 \%$.
\end{abstract}

\section{INTRODUCTION}

The Synchrotron Light Source of the Brazilian Synchrotron Light Laboratory (LNLS) is based on a 1.37 $\mathrm{GeV}$ electron storage ring, a $500 \mathrm{MeV}$ Booster Synchrotron Injector and a $120 \mathrm{MeV}$ LINAC [1].

The storage ring electron beam must stay as close as possible to a pre-defined orbit in order to obtain the needed stability for the beam lines to perform experiments. The magnets that do this function are called orbit correctors and they are dipole type magnets.

Currently, there are approximately one hundred DC current sources that supply these magnets. Because the direction of the magnetic field produced by these magnets depends on many parameters, these power supplies must be bipolar, with smooth transition through zero. Moreover, the precision, long-term and temperature stability, and ripple, must be better than 100ppm.

Some perturbations in the electron beam orbit are very fast, and the present corrector power supplies don't have enough velocity to compensate them. Therefore, a new current source was developed for the orbit corrector to meet those needs. At the limit, the required correction frequency is $50 \mathrm{~Hz}$ for small corrections.

Another disadvantage of the present orbit corrector source is its low efficiency, which implies the need for forced ventilation. This is an undesirable situation because the periodic substitution of ventilators is a time consuming and costly procedure. These aspects suggest that the new power supply must have no forced ventilation.

Finally, input power correction was implemented so the input current Total Harmonic Distortion (THD) can be minimized.

The older model (BCA) of current sources for orbit correctors in use in the storage ring is basically made up of a three-phase rectifier with a capacitive filter, providing a symmetric DC voltage source for a series regulator with Bipolar Junction Transistor (BJT) [2]. The main disadvantage of this topology is its lower efficiency, resulting in a increased size and weight, and needing forced ventilation. A second disadvantage is the line frequency of the transformer, which increases its size and weight. The advantages are the independence of the inductance load value and the elimination of the electromagnetic interference. The maximum output current and voltage are respectively $10 \mathrm{~A} / 10 \mathrm{~V}$. The measured efficiency for this current source is $39.4 \%$ and the power factor is 0.73 , for $10 \mathrm{~A}$ output current. The ventilators are substituted every three years.

A second version (BCB) of orbit corrector power supplies was developed when the $500 \mathrm{MeV}$ booster synchrotron machine was constructed [3]. Also series regulators with BJT stabilize the output current of these power supplies, allowing the required precision, with a control circuit similar the previous current source. However, the DC voltage that feed these regulators are obtained with commercial personal computers (PC) power supplies, with their control network modified so the output voltage can be adjusted to hold the average collector-emitter voltage (VCE) of the regulator BJT approximately $2 \mathrm{~V}$, which decreases its losses. In short time intervals this voltage changes to compensate output current fast variations, but the control circuit acts and compensates this change. This current source presents the following advantages in relation the previous model: 1) higher efficiency; 2) lower size and weight due to the absence of the line frequency transformer and the use of commercial PC power supplies. The main disadvantage is the use of ventilators, which are substituted every two years. The maximum output current and voltage are respectively $10 \mathrm{~A} / 10 \mathrm{~V}$. The measured efficiency for this current source is $64.5 \%$ and the power factor is 0.535 , for $10 \mathrm{~A}$ output current.

\section{NEW POWER SUPPLY DESCRIPTION}

The new proposed topology (BCC) for the orbit corrector current source is showed in fig. 1 [4]. In relation to Booster (BCC) power supplies, the PC power supply was substituted by an isolated half-bridge inverter, with a high frequency rectifier in its output. A power factor 
corrector (PFC) was added to the input circuit. Each one of the blocks will be briefly described next.

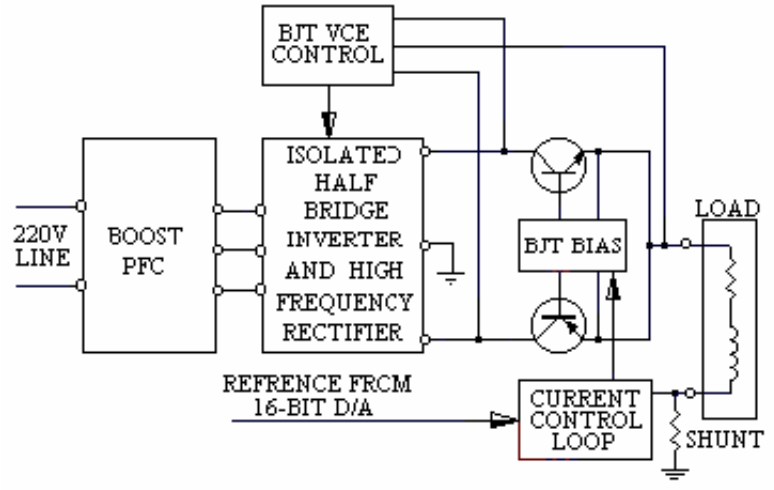

Figure 1: Topology for the new orbit corrector current source.

\section{Power Factor Corrector (PFC)}

The power factor implemented uses the Boost configuration in the continuous current mode. Its function is to obtain an input current and voltage with the same waveform, providing a stabilized voltage for the inverter.

The PWM control is made by the L4981A integrated circuit. The switch used is an Insulated Gate Bipolar Transistor (IGBT) integrated in a single module (SEMIKRON SK60GAL) with the diode. The IGBT driving is made directly by the L4981A, without additional drive circuit. The switching frequency is $50 \mathrm{kHz}$.

The output capacitance is divided in two capacitors, which gives a necessary symmetric voltage to the next stage.

\section{Isolated Half Bridge Inverter}

The regulated PFC output voltage supplies the isolated inverter. The main function of this stage is to provide the necessary voltage so the next stage BJT collector-emitter voltage is kept close to $2 \mathrm{~V}$. This voltage control is made by the pulse width modulation (PWM) of the isolated inverter. For transients of the reference voltage, the BJT will try to compensate the difference in the output current, changing its VCE. So the inverter IGBT pulse width is increased to a maximum giving the necessary load overvoltage (35V maximum) to obtain a faster response.

The VCE control circuit generates an error voltage proportional to the difference between the active BJT collector-emitter voltage and the pre-defined desired value. This error is sent to the PWM integrated circuit (SG3525A) by a PI amplifier. The IGBT isolated gate signals is obtained by a commercial drive circuit. The switching frequency is $43 \mathrm{kHz}$. The chosen IGBTs are SEMIKRON SK45GB models.

\section{BJT Series Regulator}

The BJT series regulator used is similar to that others orbit corrector power supplies. This stage is still necessary to obtain the zero soft transition and the high stability required.
The main change in the Series Regulator is the BJT heat sink layout. It was placed outside the power supply, so the heat exchange efficiency was increased, which allow the elimination of the forced ventilation. This heat sink is also used to the output inverter fast diodes.

\section{TESTS AND MEASUREMENTS}

The tests with a prototype were satisfactory and ten units were built. Eight of them have being used in the Storage Ring Orbit Correctors and the others are spare units.

Many tests and measurements were exhaustively performed with all units so this model could be characterized. We describe the main tests and results below. The used load was a typical Orbit Corrector with a series resistor representing the cable losses, so the total resistance was close to $1.3 \Omega$ and the inductance $26 \mathrm{mH}$, unless explicitly stated otherwise.

\section{Input Power Factor and Efficiency}

The input and output voltage and current were measured to calculate the power factor and efficiency for $0,1 \mathrm{~A}, 5 \mathrm{~A}$ and $10 \mathrm{~A}$, for both polarities. The more relevant results are the power factor better than $98.5 \%$ and the efficiency better than $62 \%$, both for $+/-10 \mathrm{~A}$. The input power with $0 \mathrm{~A}$ was $21 \mathrm{~W}$. Fig. 2 shows an example of the obtained waveforms for $10 \mathrm{~A} / 12.8 \mathrm{~V}$ output.

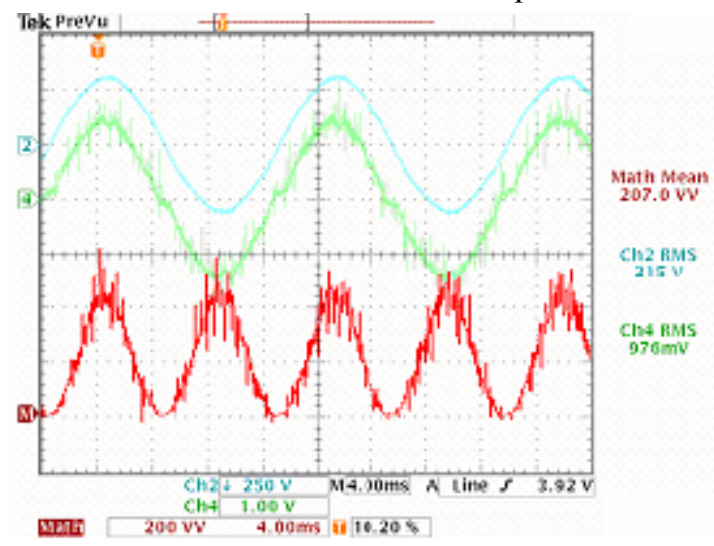

Figure 2: Input voltage (upper trace, 250V/div), current (middle trace, $1 \mathrm{~A} / \mathrm{div}$ ) and power (lower trace, 200W/div) for $10 \mathrm{~A} / 12.8 \mathrm{~V}$ output.

\section{Ripple Measurements}

The rms and peak-to-peak output current ripple was measured for each $1 \mathrm{~A}$ from $-10 \mathrm{~A}$ to $+10 \mathrm{~A}$. In the worst case it was close to $2 \mathrm{~mA}_{\mathrm{pp}}\left(500 \mu \mathrm{A}_{\mathrm{rms}}\right)$, which happened for absolute current values within $1 \mathrm{~A}$ and $2 \mathrm{~A}$. Fig. 3 shows the output current ripple for 1A.

\section{Stability Measurements}

Stability measurements were done for $0,1 \mathrm{~A}, 5 \mathrm{~A}$ and $10 \mathrm{~A}$, for both polarities, during 24 hours, at least. The maximum ambient temperature variation during the test was $7^{\circ} \mathrm{C}$. In the worst case, the stability was $2.8 \mathrm{~mA}$ (at $+10 \mathrm{~A}$ ), which is shown in Fig. 4. 


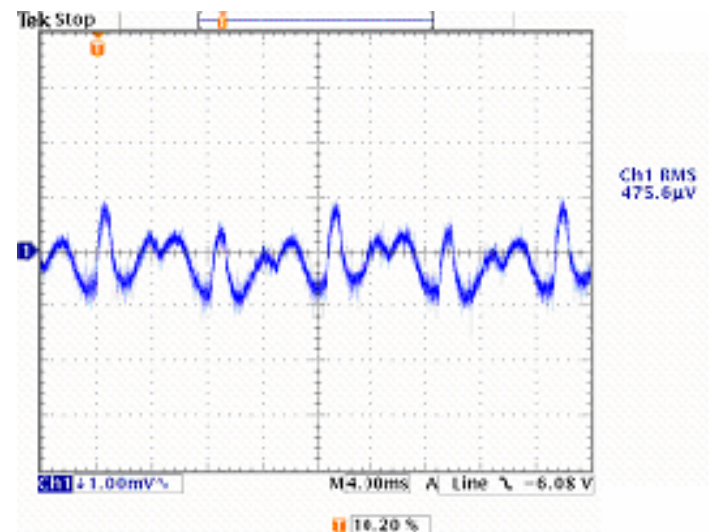

Figure 3: Output current ripple (1mA/div) for $1 \mathrm{~A}$

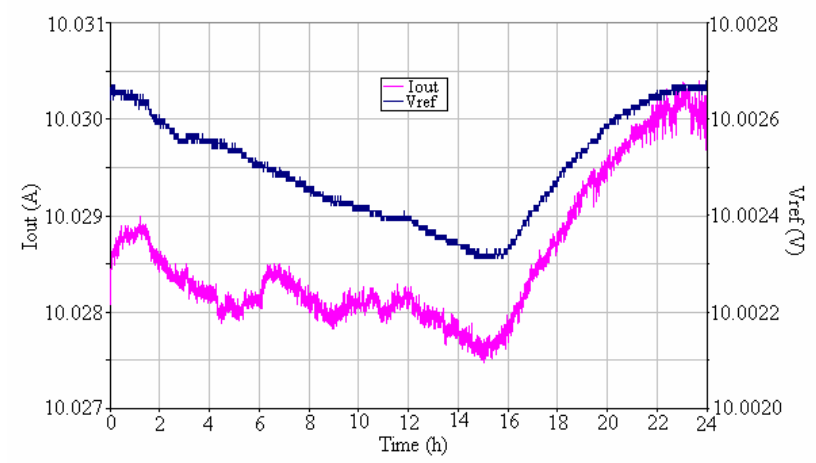

Figure 4: Output current and reference voltage during stability test for $+10 \mathrm{~A}$

\section{Reference Voltage Step Response}

Reference voltage step response measurements were done for steps of $10 \mathrm{~A}, 1 \mathrm{~A}$ and $100 \mathrm{~mA}$, around $+10 \mathrm{~A}, 0$ and $-10 \mathrm{~A}$. The worst results were: $18 \mathrm{~ms}$ for $10 \mathrm{~A}$ step, $2.5 \mathrm{~ms}$ for $1 \mathrm{~A}$ step and $1.2 \mathrm{~ms}$ for $100 \mathrm{~mA}$ step. Figure 5 shows the output current and voltage and reference voltage for a transition from 0 to $-10 \mathrm{~A}$.

\section{Other Measurements}

Other measurements were done, such as current regulation in relation to input voltage and load variations. The result for the first test was $0.4 \mathrm{~mA}$ for a input voltage step of $26 \%$. For the second test the regulation obtained was $0.2 \mathrm{~mA}$ for a $26 \%$ load resistance variation.

The hold-up time was measured and it was $220 \mathrm{~ms}$ for $10 \mathrm{~A}$ absolute output current value. For these same values, the warm-up time found was 15 minutes with a output current difference of $20 \mathrm{~mA}$ during this time.

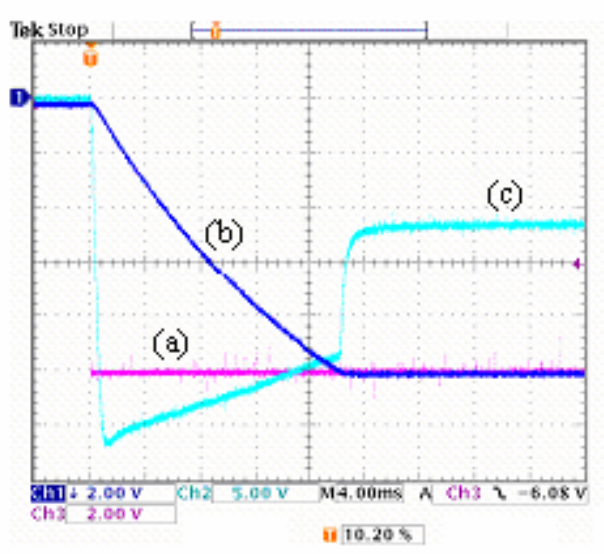

Figure 5: Output voltage (a) (2V/div) and current (b) $(2 \mathrm{~A} / \mathrm{div})$ and reference voltage (c) $(5 \mathrm{~V} / \mathrm{div})$ for a transition from 0 to $-10 \mathrm{~A}$

\section{CONCLUSION}

Up to now the performance of the new power supplies has been satisfactory. Initial problems with the output BJT were solved by replacing them with another model with greater breakdown voltage.

The measurements done showed that the specifications were reached, except for the long-time stability (140ppm instead of expected 100ppm). However, within controlled ambient temperature rooms, as is the Storage Ring building, the results should be better. Anyway, the results obtained were far better than those for older power supply model.

For the next units, some improvements are being implemented, such as measurement of some internal parameters such as voltages and temperatures, shown in a Liquid Crystal Display (LCD), and Ethernet Communication to download these measurements.

\section{REFERENCES}

[1] www.lnls.br

[2] A. C. de Lira, J. A. Pomilio, D. Wisnivesky, "Power Supplies for the LNLS Magnets", PAC'89, Chicago, March 1989, p.1922.

[3] A. C. de Lira, A. R. Silva, L. H. Oliveira and G. Monteiro, "Power Supplies for the 500Mev Booster Synchrotron at the Brazilian Synchrotron Light Laboratory", COBEP'01, Florianópolis, November 2001, p. 541.

[4] C. Rodrigues and A. R. Silva, "A New DC Bipolar Current Source For Orbit Correctors", COBEP'05, Recife, June 2005, p.636. 